\title{
Breaking Resistance: Is There Still a Reason for Clopidogrel in Acute STEMI?
}

\author{
Editorial to: "Prasugrel Versus High Dose Clopidogrel to Overcome Early High \\ on Clopidogrel Platelet Reactivity in Patients with ST Elevation Myocardial Infarction" \\ by $D$. Alexopoulos et al.
}

\author{
Andreas Schäfer
}

Published online: 25 September 2012

(C) Springer Science+Business Media, LLC 2012

Acute ST-elevation myocardial infarction (STEMI) is the sudden and life-threatening manifestation of coronary artery disease (CAD) leading to occlusion of a major coronary artery. Current guidelines favor primary percutaneous coronary intervention (PCI) for STEMI treatment $[1,2]$. Dual antiplatelet treatment with acetylsalicylic acid and a $\mathrm{P} 2 \mathrm{Y}_{12}$ receptor blocker is the standard of care following PCI. The guideline recommendation that "clopidogrel should be given as soon as possible to all patients with STEMI undergoing PCI" at the earliest possible time by a loading dose of at least $300 \mathrm{mg}$ or $600 \mathrm{mg}$ has led to ambulance-based clopidogrel loading in STEMI patients in some countries [1]. However, during the acute STEMI state nausea, vomiting and stress as well as pharmacological interventions such as morphine-based analgesia might impede enteral absorption of clopidogrel and, thereby, its activation to the active metabolite. Following absorption, $85 \%$ of the inactive prodrug clopidogrel is already hydrolyzed by circulating blood esterases to an inactive metabolite before the remaining $15 \%$ undergoes hepatic metabolization by cytochrome P450 isoenzymes to generate the active metabolite [3]. When impaired responsiveness, which by consensus is currently denominated "high on-treatment platelet reactivity" [4], is defined based on the risk for potential stent thrombosis, a high proportion of patients in a real-world setting are suboptimal responders to clopidogrel in daily practice [5]. Only rare data are available regarding clopidogrel metabolism in STEMI patients, and those available indicate slower

\footnotetext{
A. Schäfer $(\bowtie)$

Klinik für Kardiologie und Angiologie,

Medizinische Hochschule Hannover,

Carl-Neuberg-Str. 1,

30625 Hannover, Germany

e-mail: schaefer.andreas@mh-hannover.de
}

and less efficient metabolism as in stable patients/volunteers [6]. These considerations might be of particular importance as only oral $\mathrm{P} 2 \mathrm{Y}_{12}$ blockers are currently clinically available.

In this issue of Cardiovascular Drugs and Therapy, Alexopoulos et al. assessed $\mathrm{P} 2 \mathrm{Y}_{12}$ reactivity $2 \mathrm{~h}$ following a $600 \mathrm{mg}$ loading dose of clopidogrel in STEMI patients [7]. Interestingly, this is the exact time frame that the ESC guidelines (irrespective of the lack of data to support the assumption) state as "optimal" for clopidogrel. The $2 \mathrm{~h}$ loading time was initially based on the fact that after such loading the glycoprotein IIb/IIIa antagonist abciximab did not provide a reduction in major cardiovascular events in elective PCI [8]. However, once patients had an acute coronary syndrome and were troponine-positive, this loading regime was not able to completely substitute for glycoprotein IIb/IIIa antagonism [9].

In the current study, the majority of STEMI patients had high on-treatment platelet reactivity $2 \mathrm{~h}$ after clopidogrel loading. They were, therefore, randomized to receive either an increased clopidogrel maintenance dose or were switched to prasugrel including a loading dose of $60 \mathrm{mg}$. Those on higher clopidogrel maintenance dose also missed to achieve a significant difference in the measurement compared to the time of randomization within the next $2 \mathrm{~h}$. In contrast, those randomized to prasugrel rapidly achieved sufficient platelet inhibition. $24 \mathrm{~h}$ after randomization, the majority of patients in the clopidogrel group were still in a state of high ontreatment platelet reactivity, whereas all but one prasugreltreated patient showed sufficient platelet inhibition. The data clearly show that clopidogrel fails to provide sufficient platelet inhibition in the early phase of STEMI. The 2010 ESC guidelines on myocardial revascularization have put clopidogrel loading for STEMI patients into perspective with the newer and more potent $\mathrm{P}_{2} \mathrm{Y}_{12}$ blockers by stating that clopidogrel only "should be used primarily if the more 
effective ADP receptor blockers are contraindicated or unavailable" [10].

In particular, STEMI patients show a weaker response to clopidogrel loading than stable CAD patients undergoing PCI [11]. Previously, Heestermans et al. demonstrated that compared to healthy controls STEMI patients achieve lower maximal plasma levels of clopidogrel and its active metabolite, require longer time to reach maximal plasma levels, and have decreased exposition to the active clopidogrel metabolite [6]. Therefore, all the kinetic data derived from stable patients or even healthy volunteers might not be easily transferable to the STEMI population. Prasugrel, when compared to clopidogrel, achieves more rapid and consistently sufficient platelet inhibition as demonstrated in the phase II study PRINCIPLE-TIMI 44 [12] and in patients with acute coronary syndromes in a sub-study of the phase III TRITON trial [13].

In conclusion, the current study by Alexopoulos et al. documents that clopidogrel is no option for rapid and efficient $\mathrm{P} 2 \mathrm{Y}_{12}$ antagonism in STEMI patients. It underlines, that more efficient platelet inhibition by prasugrel achieves potent $\mathrm{P} 2 \mathrm{Y}_{12}$ inhibition more rapidly and more effectively than clopidogrel.

\section{References}

1. Van de Werf F, Bax J, Betriu A, Blomstrom-Lundqvist C, Crea F, Falk V, et al. Management of acute myocardial infarction in patients presenting with persistent ST-segment elevation: the Task Force on the Management of ST-Segment Elevation Acute Myocardial Infarction of the European Society of Cardiology. Eur Heart J. 2008;29:2909-45.

2. Antman EM, Hand M, Armstrong PW, Bates ER, Green LA, Halasyamani LK, et al. 2007 Focused update of the ACC/AHA 2004 guidelines for the management of patients with ST-elevation myocardial infarction: a report of the American College of Cardiology/American Heart Association task force on practice guidelines: developed in collaboration with the Canadian Cardiovascular Society endorsed by the American Academy of Family Physicians: 2007 writing group to review new evidence and update the ACC/AHA 2004 guidelines for the management of patients with ST-elevation myocardial infarction, writing on behalf of the 2004 writing committee. Circulation. 2008;117:296-329.
3. Savi P, Pereillo JM, Uzabiaga MF, Combalbert J, Picard C, Maffrand JP, et al. Identification and biological activity of the active metabolite of clopidogrel. Thromb Haemost. 2000;84:891-6.

4. Bonello L, Tantry US, Marcucci R, Blindt R, Angiolillo DJ, Becker R, et al. Consensus and future directions on the definition of high on-treatment platelet reactivity to adenosine diphosphate. $\mathrm{J}$ Am Coll Cardiol. 2010;56:919-33.

5. Schäfer A, Weinberger S, Flierl U, Eigenthaler M, Störk S, Walter $\mathrm{U}$, et al. ADP-induced platelet aggregation frequently fails to detect impaired clopidogrel-responsiveness in patients with coronary artery disease compared to a P2Y12-specific assay. Thromb Haemost. 2008;100:618-25.

6. Heestermans AA, van Werkum JW, Taubert D, Seesing TH, von Beckerath N, Hackeng CM, et al. Impaired bioavailability of clopidogrel in patients with a ST-segment elevation myocardial infarction. Thromb Res. 2008;122:776-81.

7. Alexopoulos D, Theodoropoulos KC, Stavrou EF, Xanthopoulou I, Kassimis G, Tsigkas G et al. Prasugrel versus high dose clopidogrel to overcome early high on clopidogrel platelet reactivity in patients with ST elevation myocardial infarction. Cardiovasc Drugs Ther 2012;26:this issue

8. Kastrati A, Mehilli J, Schuhlen H, Dirschinger J, Dotzer F, ten Berg JM, et al. A clinical trial of abciximab in elective percutaneous coronary intervention after pretreatment with clopidogrel. N Engl J Med. 2004;350:232-8.

9. Kastrati A, Mehilli J, Neumann FJ, Dotzer F, ten Berg J, Bollwein $\mathrm{H}$, et al. Abciximab in patients with acute coronary syndromes undergoing percutaneous coronary intervention after clopidogrel pretreatment: the ISAR-REACT 2 randomized trial. JAMA. 2006;295:1531-8.

10. Wijns W, Kolh P, Danchin N, Di Mario C, Falk V, Folliguet T, et al. Guidelines on myocardial revascularization: The Task Force on Myocardial Revascularization of the European Society of Cardiology (ESC) and the European Association for CardioThoracic Surgery (EACTS). Eur Heart J. 2010;31:2501-55.

11. Schäfer A, Flierl U, Kössler J, Seydelmann N, Kobsar A, Störk S, et al. Early determination of clopidogrel responsiveness by platelet reactivity index identifies patients at risk for cardiovascular events after myocardial infarction. Thromb Haemost. 2011;106:141-8.

12. Wiviott SD, Trenk D, Frelinger AL, O'Donoghue M, Neumann FJ, Michelson AD, et al. Prasugrel compared with high loading- and maintenance-dose clopidogrel in patients with planned percutaneous coronary intervention: the Prasugrel in Comparison to Clopidogrel for Inhibition of Platelet Activation and AggregationThrombolysis in Myocardial Infarction 44 trial. Circulation. 2007;116:2923-32.

13. Michelson AD, Frelinger III AL, Braunwald E, Downey WE, Angiolillo DJ, Xenopoulos NP, et al. Pharmacodynamic assessment of platelet inhibition by prasugrel vs. clopidogrel in the TRITONTIMI 38 trial. Eur Heart J. 2009;30:1753-63. 